\title{
Examining racial and ethnic trends and differences in annual healthcare expenditures among a nationally representative sample of adults with arthritis from 2008 to 2016
}

\author{
Antoinette L. Spector ${ }^{1,2}$, Sneha Nagavally², Aprill Z. Dawson², Rebekah J. Walker and Leonard E. Egede ${ }^{2,3^{*}}$ (1)
}

\begin{abstract}
Background: Disparities in health care utilization and outcomes for racial and ethnic minorities with arthritis are well-established. However, there is a paucity of research on racial and ethnic differences in healthcare expenditures and if this relationship has changed over time. Our objectives were to: 1) examine trends in annual healthcare expenditures for adults with arthritis by race and ethnicity, and 2) determine if racial and ethnic differences in annual healthcare expenditures were independent of other factors such as healthcare access and functional disability.
\end{abstract}

Methods: We used the Medical Expenditures Panel Survey (2008-2016) to examine trends in annual healthcare expenditures within and between racial and ethnic groups with arthritis $(n=227,663)$. A two-part model was used to estimate the marginal differences in expenditures by race and ethnicity after adjusting for relevant covariates, including the impact of healthcare access.

Results: Between 2008 and 2016, there were no significant changes in unadjusted healthcare expenditures within any of the racial and ethnic groups, but the trend among non-Hispanic whites did differ significantly from Hispanics and Other. In fully adjusted analysis, mean annual expenditures for non-Hispanic whites was \$946, \$939, and \$1178 more than non-Hispanic blacks, Hispanics, and Other, respectively $(p<.001)$. Healthcare access also independently explained expenditure differences in this population with adults who delayed care spending significantly more (\$2629) versus those who went without care spending significantly less (-\$1591).

Conclusions: Race and ethnicity are independent drivers of healthcare expenditures among adults with arthritis independent of healthcare access and functional disability. This underscores the need for ongoing research on the factors that influence persistent racial and ethnic differences in this population.

Keywords: Arthritis, Race, Ethnicity, Healthcare expenditures, Medical expenditure panel survey

\footnotetext{
* Correspondence: legede@mcw.edu

${ }^{2}$ Center for Advancing Population Science, Medical College of Wisconsin, 8701 Watertown Plank Rd., Milwaukee, WI 53226, USA

${ }^{3}$ Department of Medicine, Division of General Internal Medicine, Medical College of Wisconsin, 8701 Watertown Plank Rd., Milwaukee, WI 53226, USA

Full list of author information is available at the end of the article
}

C C The Author(s). 2020 Open Access This article is licensed under a Creative Commons Attribution 4.0 International License, which permits use, sharing, adaptation, distribution and reproduction in any medium or format, as long as you give appropriate credit to the original author(s) and the source, provide a link to the Creative Commons licence, and indicate if changes were made. The images or other third party material in this article are included in the article's Creative Commons licence, unless indicated otherwise in a credit line to the material. If material is not included in the article's Creative Commons licence and your intended use is not permitted by statutory regulation or exceeds the permitted use, you will need to obtain permission directly from the copyright holder. To view a copy of this licence, visit http://creativecommons.org/licenses/by/4.0/ The Creative Commons Public Domain Dedication waiver (http://creativecommons.org/publicdomain/zero/1.0/) applies to the data made available in this article, unless otherwise stated in a credit line to the data. 


\section{Background}

Arthritis (osteoarthritis and rheumatoid arthritis) impacts more than 65 million people in the United States, is the leading cause of disability among adults, and results in annual health care expenditures that exceed $\$ 600$ billion annually [1-4]. Common medical services used to manage the joint pain and stiffness that accompany arthritis include office visits with primary care and specialty physicians, prescription drugs, physical and occupational therapy, and surgical procedures $[4,5]$. Thus, it is estimated that adults with arthritis spend $\$ 1000$ more annually on health care, compared to those without this condition $[4,6]$.

Although people with arthritis are engaging with the healthcare environment regularly, racial and ethnic minorities use fewer health care services than nonHispanic Whites (NHW) [4, 7, 8]. Non-Hispanic Blacks (NHB) and Hispanics are less likely than non-Hispanic Whites to have rehabilitation services, see an orthopedic specialist, undergo a total joint arthroplasty, or utilize complementary and alternative medicine (CAM) to manage their condition [8-18]. Further, Hispanic and Asian-Americans with arthritis are approximately three and four times more likely, respectively, to have forgone any type of treatment compared to NHW [11].

There are several explanations posited for these differences including a reduced preference for, less access to, and worse outcomes with conventional medical services. Some studies have found NHB to prefer nontraditional treatment methods, such as natural remedies and spirituality, and to expect worse outcomes with surgical management $[10,18-21]$. There is also evidence that racial and ethnic minorities experience greater barriers to utilizing traditional services to treat their arthritis, such as lower socioeconomic status and higher rates of being publicly insured or uninsured [11, 22, 23]. This disparity in access could result in greater unmet health care need and worse health status, as well as increased health care costs over time [10, 14, 24-27].

Notwithstanding our awareness of disparities in health care utilization by racial and ethnic minorities, there has been little attention paid to how this has impacted people with arthritis over time. While Raval and Vyas examined trends in healthcare expenditures among people with arthritis and found less utilization by racial and ethnic minorities across service categories between 2008 and 2014, they did not analyze if there were differences in trends between racial and ethnic groups [4]. Moreover, there have been changes in the health care landscape that may have impacted the magnitude of racial and ethnic differences. The full implementation of the Patient Protection and Affordable Care Act (ACA), in 2014, has led to increased health care utilization by racial and ethnic minorities and reduced their likelihood of forgoing or delaying care [28-30]. Therefore, the purpose of this study was twofold. We first wanted to examine trends in annual healthcare expenditures for adults with arthritis by race and ethnicity and identify if there were significant differences within and between groups. Second, we wanted to identify if there were significant racial and ethnic differences in annual healthcare expenditures among people with arthritis, independent of other factors such as healthcare access and functional disability.

\section{Methods}

\section{Data source and sample}

We retrospectively examined an overall sample of 227, 663 individuals age 18 years and older and a subsample of 53,058 individuals with a self-reported diagnosis of arthritis between 2008 and 2016 using the full-year household consolidated data files of the Medical Expenditure Panel Survey (MEPS) [31]. MEPS is an annual national household survey that derives estimates of healthcare utilization, health status, and health insurance coverage from a nationally representative sample of the civilian noninstitutionalized U.S. population [32]. A complex, stratified sampling strategy is used to obtain a unique and representative sample for each year that the survey is administered. By combining data from a series of years, this analysis provides a series of cross-sectional snapshots overtime. To provide three points in time to assess trends while also maintaining sufficient sample size in the individual time periods, we divided the total sample between three different time periods (20082010, 2011-2013, 2014-2016). The 2008-2010 sample had a total of 72,415 individuals with 16,685 reporting an arthritis diagnosis. The 2011-2013 sample had a total of 79,160 individuals with 17,843 reporting an arthritis diagnosis. The 2014-2016 sample had a total of 75,482 individuals with 18,530 reporting an arthritis diagnosis.

\section{Dependent variable}

The dependent variable was total direct healthcare expenditures. This includes the sum of payments for medical services such as office-based visits, inpatient stays, emergency room visits, home healthcare visits, and prescription drug costs. Annual total expenditures account for an individual's out-of-pocket expenses, payments made by public and private insurance providers, and other sources during the calendar year. Expenditure data is collected at the household level and through medical providers [32].

\section{Independent variable}

The primary independent variable was race/ethnicity. We grouped the sample into four categories: nonHispanic white (NHW), non-Hispanic black (NHB), 
Hispanic (HSP), and non-Hispanic other (OTH). OTH includes those who were non-Hispanic and identified as Asian, American Indian/Alaska Native, Native Hawaiian/ Pacific Islander, or multiracial.

\section{Covariates}

The remaining variables were included based on the Andersen and Newman Framework of Healthcare Utilization, and were categorized as predisposing, enabling and need factors [33, 34]. Andersen and Newman theorized that there are several individual determinants of healthcare utilization and provided a model to assist researchers in identifying relevant variables in their analysis [34]. Predisposing factors include characteristics that existed before the onset of illness and can be associated with differing patterns in service utilization [34]. Enabling factors are the resources available to an individual to allow them to obtain medical care [34]. Need factors are the perceived or evaluated presence of an illness that would provide a reason for an individual to obtain medical care [34]. Andersen and Newman provide suggestions of variables that could be included in each category and indicate that each variable and category are distinct enough to be included in multivariate analyses [34]. Additionally, the Andersen and Newman model has previously been used to identify relevant variables in MEPS among a population of individuals with arthritis [6].

\section{Predisposing}

Predisposing factors included age, sex, region, and metropolitan statistical area (MSA). Region was categorized as Northeast, Midwest, South, and West.

\section{Enabling}

Enabling factors were education, employment status, poverty level, insurance status, and access to medical care. Education was dichotomized as having less than a bachelor's degree versus having at least a bachelor's degree. Employment was divided into employed versus unemployed. Poverty level was categorized by the percentage of family income in relation to the federal poverty line into five income groups: high ( $>$ to $400 \%)$, middle $(<400 \%$ and $\geq 200 \%$ ), low ( $<200$ and $\geq 125 \%$ ), near poor ( $>125 \%$ and $\geq 100 \%$ ), or poor $(<100 \%)$. Insurance status was grouped by those with any private insurance, only publicly insured, or uninsured. Access to medical care was determined in two ways. The first type was based on a yes or no response to a question asking if the individual delayed needed care during the calendar year. The second was based on a yes or no response to whether the individual went without needed medical care during the calendar year.

\section{Need}

Need factors were comorbidities, body mass index (BMI), self-reported joint pain, and needing help with activities of daily living (ADL) or instrumental activities of daily living (IADL). We summed the number of selfreported medical conditions (high blood pressure, heart disease, stroke, emphysema, chronic bronchitis, high cholesterol, cancer, diabetes) to create a comorbidity count. We categorized BMI into four groups including normal weight $(18.5$ to $<25)$, underweight $(<18.5)$, overweight $(25$ to $<30)$, and obese (30 or higher). Joint pain was included as a binary variable based on a response of either yes or no. For ADL and IADL, we dichotomized each variable based on whether a person responded either yes or no to needing help completing ADL (examples: feeding, bathing, dressing, toileting) or IADL (examples: using the telephone, paying bills, taking medications, preparing light meals, doing laundry, going shopping).

\section{Statistical analyses}

We first calculated demographics of the 2008-2016 pooled sample using means, frequencies, and percentages. Second, we identified linear trends in mean annual healthcare expenditures and prevalence of arthritis by race and ethnicity in adults (18 years or older) with a self-reported diagnosis of arthritis between 2008 and 2016. We executed the Cochran Armitage test to identify significant differences between trend lines and unadjusted linear models to identify significant differences within a single trend line. Following Manning and Mullahy's recommendation on handling healthcare expenditure data, we then used a two-part statistical model to assess the likelihood of a zero or positive healthcare expenditure and the spending differences among those who had greater than a zero amount of expenditure [35, 36]. This approach has been incorporated in previously published research using the MEPS dataset [37]. Using this method, we assessed both binomial and positive distributions of healthcare expenditures. To assess the likelihood of zero expenditure versus positive expenditure, we implemented a probit model followed by a gamma distributed and log link generalized linear model (GLM) to assess the differences among the population who had positive healthcare expenditures. The GLM gamma distribution and log link in the second part of the model was used to account for the skewness of the medical expenditure data by transforming medical expenditures into log scale. GLM gamma family and log link were chosen because of their ability to avoid bias associated with retransformation to raw scale, it is able to handle heteroscedasticity in non-negative data, and is a more flexible methodology that is able to relax normality requirements $[38,39]$. For weighting the U.S. population, 
we implemented survey design packages which integrates sampling weights, stratum and psu clustering [40]. Finally, to calculate adjusted healthcare expenditures, we calculated average marginal effects using the post estimation commands. To confirm changes in expenditures over time were independent of inflation, we ran a second set of models adjusting expenditure by the Consumer Price Index. All analyses were performed using $\mathrm{R}$ and STATA v.15 [41]. A statistical significance of $p<0.05$ was used for all analyses.

\section{Results}

Table 1 shows the demographic characteristics of the sample. Among the total sample $(n=227,663)$ there was an overall arthritis prevalence of $23 \%(n=53,058)$ between 2008 and 2016. The sample was predominantly female (54\%) and NHW (43\%), lived in the South (38\%), and were either high $(29 \%)$ or middle $(30 \%)$ income. Most had some private insurance (57\%), less than a bachelor's degree (72\%), and were employed (63\%).

Table 2 shows the arthritis prevalence overall and for each of the four race/ethnicity categories. NHW had the highest prevalence of arthritis during each of the study periods (29-32\%), followed by NHB (26-27\%), OTH (15-16\%), and HSP (13-15\%). There were no significant differences in arthritis prevalence within or between any of the racial and ethnic groups during the study period.

Figure 1 shows mean expenditures by race and ethnicity during each time period (2008-2010, 2011-2013, and 2014-2016). NHW with arthritis had the highest mean annual expenditure during each of the study periods. There were increases in expenditures over time in each of the racial and ethnic groups. NHW spent on average $\$ 8961$ per year between 2008 and 2010 with an increase to $\$ 11,376$ per year by 2014-2016. For NHB, mean annual expenditures were $\$ 8088$ per year between 2008 and 2010 and increased to $\$ 10,240$ per year between 2014 and 2016. OTH spent $\$ 7951$ on average per year between 2008 and 2010 with an increase to $\$ 9294$ per year in 2014-2016. HSP had the lowest expenditures of the racial and ethnic groups but also increased from $\$ 7211$ per year in 2008-2010 to \$9469 per year in 20142016. While an increase in mean annual expenditures was observed across all groups from 2008 to 2010 to the 2014-2016 time period, none of the linear cost trends reached the level of significance within any of the groups. However, the Cochran-Armitage test found that there were significant differences in mean expenditure trends between racial and ethnic groups. The trends in mean expenditures were significantly different for HSP $(p=0.04)$ and OTH $(p<0.001)$ compared to NHW. There were no significant differences in mean expenditure trends between NHW and NHB.
Findings from the adjusted analyses are shown in Table 3. The adjusted model reflects marginal differences in mean annual expenditures among adults with arthritis after adjusting for predisposing, enabling, and need factors. In this model, each of the racial and ethnic minority groups had significantly less mean annual expenditures than NHW. On average, NHW had $\$ 939$ more in expenditures than HSP $(p<0.001)$, \$946 more than NHB $(p<0.001)$, and $\$ 1178$ more than those in the OTH group $(p<0.001)$. Based on the $95 \%$ confidence interval around the adjusted mean annual expenditures, there were no significant differences between the racial and ethnic minority groups. After adjustment, differences in mean expenditures were also observed over time for adults with arthritis. Compared to 2008-2010, mean expenditures increased by $\$ 750(p<0.01)$ for 2011-2013 and $\$ 900(p<0.001)$ for 2014-2016. After accounting for inflation using the Consumer Price Index, there was a marginal increase in expenditures at the $p=$ 0.09 level by $\$ 406$ for $2011-2013$ and $\$ 269(p=0.23)$ for 2014-2016.

There were several other factors that independently explained mean expenditure differences among adults with arthritis in the fully adjusted model (Table 3 ). Those who went without needed care had expenditures that were \$1591 less than those who reported that they were able to obtain needed medical care during the calendar year $(p<0.001)$. Adults with arthritis who reported delaying needed medical care had expenditures that were $\$ 2629$ more on average than those who received timely care $(p<0.001)$. Additionally, those who were uninsured had significantly lower expenditures $(-\$ 3937 ; p<0.001)$ than those with any private insurance. Needing help with ADL or IADL resulted in higher annual expenditures of about $\$ 5200$ and $\$ 3800$, respectively $(p<0.001)$. For each additional comorbidity reported by those with arthritis, there was a $\$ 1575$ increase in mean annual expenditures during the study period $(p<0.001)$.

\section{Discussion}

The goals of our study were to examine trends in annual healthcare expenditures among adults with arthritis by race and ethnicity, and to identify factors that explained differences in costs within this population using nationally representative data from 2008 to 2016 . We found that the overall arthritis prevalence remained stable during the study period overall and within each of the racial and ethnic groups. We observed a significant increase in average annual expenditures in each of the later cohorts compared to 2008 through 2010. After adjusting for inflation to 2019 dollars using the Consumer Price Index marginally, statistically significant increases in expenditures remained for 2011-2013 and 2014-2016 compared 
Table 1 Sample demographics by arthritis status in U.S. adults 2008-2016 ( $n=227,663)$

\begin{tabular}{|c|c|c|c|}
\hline \multirow{2}{*}{. } & \multirow[t]{2}{*}{ Total n (\%) } & \multicolumn{2}{|c|}{ Arthritis n (\%) } \\
\hline & & Yes & No \\
\hline All & $227,663(100)$ & $53,058(23)$ & $173,999(76)$ \\
\hline \multicolumn{4}{|l|}{ Age } \\
\hline $18-34$ & $75,029(33)$ & $2912(5)$ & $71,980(41)$ \\
\hline $35-44$ & $40,841(18)$ & $5017(9)$ & $35,740(21)$ \\
\hline $45-64$ & $75,563(33)$ & $24,112(45)$ & $51,166(29)$ \\
\hline$>=65$ & $36,230(16)$ & $21,017(40)$ & $15,113(9)$ \\
\hline \multicolumn{4}{|l|}{ Sex } \\
\hline Male & $105,808(46)$ & $19,411(37)$ & $86,106(49)$ \\
\hline Female & $121,855(54)$ & $33,647(63)$ & $87,893(51)$ \\
\hline \multicolumn{4}{|l|}{ Race/Ethnicity } \\
\hline Hispanic & $62,471(27)$ & $8637(16)$ & $53,725(31)$ \\
\hline Non-Hispanic White & $97,981(43)$ & $29,303(55)$ & 68,364 (39) \\
\hline Non-Hispanic Black & $44,672(20)$ & $11,651(22)$ & $32,896(19)$ \\
\hline Other & $22,539(10)$ & $3467(7)$ & $19,014(11)$ \\
\hline \multicolumn{4}{|l|}{ Region } \\
\hline Northeast & $36,212(16)$ & $8823(17)$ & $27,319(16)$ \\
\hline Midwest & $43,470(19)$ & $11,581(22)$ & 31,765 (18) \\
\hline South & 86,081 (38) & $21,319(40)$ & $64,527(37)$ \\
\hline West & $61,900(27)$ & $11,335(21)$ & $50,388(29)$ \\
\hline \multicolumn{4}{|l|}{ Education } \\
\hline Less than bachelor's & $142,906(72)$ & $35,022(75)$ & $108,762(72)$ \\
\hline Bachelor's degree or more & $54,868(28)$ & $11,652(25)$ & $43,163(28)$ \\
\hline \multicolumn{4}{|l|}{ Employment } \\
\hline Employed & $143,289(63)$ & $21,460(41)$ & $121,648(70)$ \\
\hline Not employed & $83,402(37)$ & $31,482(59)$ & $51,778(30)$ \\
\hline \multicolumn{4}{|l|}{ Poverty Category } \\
\hline High income [> = 400] & $66,206(29)$ & $15,104(28)$ & $50,923(29)$ \\
\hline Middle Income [> = $200 \&<400]$ & $68,321(30)$ & $15,025(28)$ & $53,099(31)$ \\
\hline Low Income [> = $125 \&<200]$ & $37,626(17)$ & $8829(17)$ & $28,690(16)$ \\
\hline Near Poor [> = $100 \&<125]$ & $13,566(6)$ & $3590(7)$ & 9946 (6) \\
\hline Poor $[<100]$ & $41,944(18)$ & $10,545(20)$ & $31,341(18)$ \\
\hline \multicolumn{4}{|l|}{ Insurance Status } \\
\hline Any Private & $129,900(57)$ & $28,239(53)$ & $101,543(58)$ \\
\hline Public only & $52,15(23)$ & $20,200(38)$ & $32,552(19)$ \\
\hline Uninsured & $44,948(20)$ & 4619 (9) & $39,904(23)$ \\
\hline \multicolumn{4}{|l|}{ Year } \\
\hline 2008-2010 & $72,625(32)$ & $16,685(31)$ & $55,730(32)$ \\
\hline 2011-2013 & $79,362(35)$ & $17,843(34)$ & $61,317(35)$ \\
\hline 2014-2016 & $75,676(33)$ & $18,530(35)$ & $56,952(33)$ \\
\hline
\end{tabular}

to 2008-2010 indicating this increase was not due to inflation. We also found that expenditure trends in Hispanic and Other racial and ethnic minorities with arthritis were significantly different than NHW during the study period with mean annual expenditures that were between $\$ 900$ and $\$ 1200$ less than NHW independent of other access and functional ability factors incorporated into our model. Although predisposing, 
Table 2 Arthritis prevalence by race and ethnicity 2008-2016 $(n=227,663)$

\begin{tabular}{|c|c|c|c|c|c|c|c|c|c|}
\hline \multirow{2}{*}{$\begin{array}{l}\text { Race/ } \\
\text { Ethnicity }\end{array}$} & \multicolumn{3}{|l|}{ 2008-2010 } & \multicolumn{3}{|l|}{ 2011-2013 } & \multicolumn{3}{|l|}{ 2014-2016 } \\
\hline & Arthritis (n) & No Arthritis (n) & Prevalence & Arthritis (n) & No Arthritis (n) & Prevalence & Arthritis (n) & No Arthritis (n) & Prevalence \\
\hline Total & 16,685 & 55,730 & $30 \%$ & 17,843 & 61,317 & $29 \%$ & 18,530 & 56,952 & $33 \%$ \\
\hline NHW & 9769 & 23,899 & $29 \%$ & 9653 & 23,436 & $29 \%$ & 9881 & 21,029 & $32 \%$ \\
\hline NHB & 3539 & 10,233 & $26 \%$ & 4093 & 11,956 & $26 \%$ & 4019 & 10,707 & $27 \%$ \\
\hline HSP & 2362 & 15,965 & $13 \%$ & 2941 & 19,229 & $13 \%$ & 3334 & 18,531 & $15 \%$ \\
\hline OTH & 1015 & 5633 & $15 \%$ & 1156 & 6696 & $15 \%$ & 1296 & 6685 & $16 \%$ \\
\hline
\end{tabular}

NHW Non-Hispanic white, NHB Non-Hispanic black, HSP Hispanic, OTH Non-Hispanic other

${ }^{a}$ No significant changes in prevalence over time within or between groups

enabling, and need factors were all identified as key drivers of medical expenditures in adults with arthritis, they did not negate the racial and ethnic differences.

Our findings are consistent with previous work on racial and ethnic differences in healthcare expenditures and builds on previous research in two important ways. First, we identified that trends in healthcare expenditures among NHW with arthritis were significantly different than HSP and OTH between 2008 and 2016. Williams et al. previously found that individuals with arthritis and joint pain had over $\$ 1600$ higher expenditures annually despite additional differences by race and functional limitations [6]. Among adults with arthritis, Raval and Vyas found that unadjusted annual healthcare expenditures were consistently lower among all racial and ethnic minorities compared to NHW during each year of their study (2008-2014) [4]. Taken together, these findings suggest an ongoing need to study racial and ethnic differences in healthcare expenditures among individuals with arthritis and how these differences are changing over time. Given the dynamic nature of the healthcare environment, analyses are also warranted to examine the specific factors that are influencing differing trends in healthcare expenditures within this population.

The second unique contribution of this analysis is identifying that healthcare expenditures among racial and ethnic minorities remained significantly lower than NHW after adjusting for predisposing, enabling, and need factors, including healthcare access and activities of daily living. Although previous research has not specifically examined cost, researchers have posited that healthcare access, socioeconomic status, and education might explain differences in healthcare utilization by racial and ethnic minorities with arthritis [14, 24]. Our study provides evidence that these factors do not fully account for differences in mean annual expenditures. Health beliefs are considered an important aspect of healthcare utilization and may also impact expenditures [33, 34]. Previous research has found that racial and ethnic minorities with arthritis prefer complementary and alternative therapies to

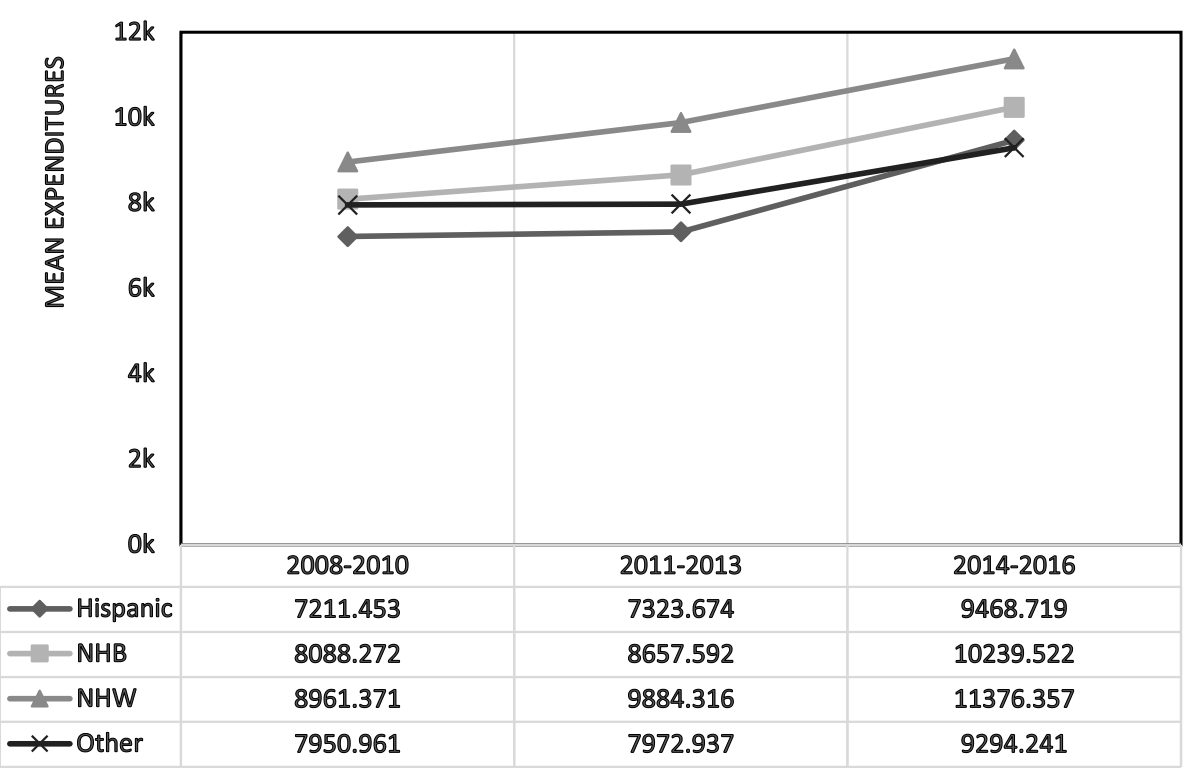

Fig. 1 Mean annual expenditures among adults with arthritis by race and ethnicity 2008-2016 
Table 3 Two-part regression model: adjusted marginal differences in healthcare expenditures among U.S. adults with arthritis by race and ethnicity $2008-2016(n=53,058)$

\begin{tabular}{|c|c|c|c|}
\hline & Marginal difference & 95\% Confidence interval & $P$-value \\
\hline \multicolumn{4}{|l|}{ Race/Ethnicity } \\
\hline Non-Hispanic White (Reference) & - & - & \\
\hline Non-Hispanic Black & $-\$ 946$ & $-\$ 1355$ to $-\$ 537$ & $* * *$ \\
\hline Hispanic & $-\$ 939$ & $-\$ 480$ to $-\$ 1397$ & $* * *$ \\
\hline Other & $-\$ 1178$ & $-\$ 1713$ to $-\$ 644$ & $* * *$ \\
\hline \multicolumn{4}{|l|}{ Year } \\
\hline 2008-2010 (Reference) & - & - & \\
\hline 2011-2013 & $\$ 758$ & $\$ 341$ to $\$ 1176$ & ** \\
\hline 2014-2016 & $\$ 897$ & $\$ 51$ to $\$ 1281$ & $* * *$ \\
\hline \multicolumn{4}{|l|}{ Predisposing } \\
\hline Age & $-\$ 24.36$ & $-\$ 39$ to $-\$ 9$ & $* * *$ \\
\hline \multicolumn{4}{|l|}{ Sex } \\
\hline Male (Reference) & - & - & \\
\hline Female & $\$ 362$ & $\$ 22$ to $\$ 701$ & * \\
\hline \multicolumn{4}{|l|}{ Region } \\
\hline Northeast (Reference) & - & - & \\
\hline Midwest & $-\$ 86$ & $-\$ 830$ to $\$ 99$ & \\
\hline South & $-\$ 451$ & $-\$ 883$ to $-\$ 20$ & \\
\hline West & $-\$ 45$ & $-\$ 524$ to $\$ 434$ & \\
\hline \multicolumn{4}{|l|}{ Enabling } \\
\hline \multicolumn{4}{|l|}{ Education } \\
\hline < Bachelor's Degree (Reference) & - & - & \\
\hline$>=$ Bachelor's degree & $\$ 1119$ & $\$ 708$ to $\$ 1530$ & \\
\hline \multicolumn{4}{|l|}{ Employment } \\
\hline Employed (Reference) & - & - & \\
\hline Unemployed & $\$ 2305$ & $\$ 1839$ to $\$ 2771$ & \\
\hline \multicolumn{4}{|c|}{ Poverty Category [family income to poverty line \%] } \\
\hline High income [> = 400] (Reference) & - & - & \\
\hline Middle Income [> = $200 \&<400]$ & $-\$ 851$ & $-\$ 1295$ to $-\$ 407$ & ** \\
\hline Low Income [> = $125 \&<200]$ & $-\$ 845$ & $-\$ 1415$ to $-\$ 275$ & * \\
\hline Near Poor $[>=100 \&<125]$ & $-\$ 1035$ & $-\$ 1609$ to $-\$ 460$ & ** \\
\hline Poor $[<100]$ & $-\$ 966$ & $-\$ 1518$ to $-\$ 415$ & $* *$ \\
\hline \multicolumn{4}{|l|}{ Insurance Status } \\
\hline Any Private (Reference) & - & - & \\
\hline Public only & $-\$ 830$ & $-\$ 1214$ to $-\$ 445$ & $* * *$ \\
\hline Uninsured & $-\$ 3937$ & $-\$ 4500$ to $-\$ 3373$ & *** \\
\hline \multicolumn{4}{|l|}{ Access to Care } \\
\hline Able to get care (Reference) & - & - & \\
\hline Unable to get care & $-\$ 1591$ & $-\$ 2152$ to $-\$ 1030$ & *** \\
\hline No delays in receiving care (Reference) & - & - & \\
\hline Delayed in receiving care & $\$ 2629$ & $\$ 1905$ to $\$ 3353$ & $* * *$ \\
\hline \multicolumn{4}{|l|}{ Need } \\
\hline Comorbidity Count (0-8) & $\$ 1575$ & $\$ 1427$ to $\$ 1722$ & $* * *$ \\
\hline
\end{tabular}


Table 3 Two-part regression model: adjusted marginal differences in healthcare expenditures among U.S. adults with arthritis by race and ethnicity 2008-2016 $(n=53,058)$ (Continued)

\begin{tabular}{lll}
\hline & Marginal difference & $95 \%$ Confidence interval \\
\hline Functional Limitations & - & - \\
Did not need help with ADL (Reference) & $\$ 5241$ & $\$ 4184$ to $\$ 6298$ \\
Needed help with ADL & - & - \\
Did not need help with IADL (Reference) & $\$ 3829$ & $\$ 3118$ to $\$ 4540$ \\
Needed help with IADL & - & - \\
BMI & $\$ 1407$ & $\$ 205$ to $\$ 2609$ \\
Normal weight (Reference) & $\$ 91$ & $-\$ 358$ to $\$ 540$ \\
Under weight & $\$ 452$ & $\$ 40$ to $\$ 863$ \\
Overweight & & \\
Obese & - & $\$ 3 * 14$ to $\$ 1785$ \\
Joint Pain & $\$ 1349$ & $*$
\end{tabular}

conventional medical care, which would generally be excluded from healthcare expenditures $[10,18,19,21]$. The utilization of and expenses for complementary and alternative therapies could be an important part of understanding racial and ethnic differences in expenditures among adults with arthritis.

We did find notable differences in annual expenditures among adults with arthritis who encountered barriers to medical care. A study by Molina et al. concluded that delays in treatment resulted in worse clinical outcomes in a community sample of adults with rheumatoid arthritis [42]. Our study is the first, to our knowledge, to quantify the direct cost of delaying needed care in a nationally representative sample of adults with arthritis. We found that those that delayed care spent \$2629 more on average than those receiving timely care. Additional research is needed to examine the circumstances surrounding the delayed care and could provide opportunities for intervention that reduce the financial burden and improve clinical outcomes in this population.

Despite the novelty of our findings, this study did have some limitations. Our sample was identified from a cohort of participants who self-reported an arthritis diagnosis. Self-report data is subject to recall bias and may have impacted our prevalence estimates. However, the arthritis prevalence identified by MEPS has been shown to agree with estimates in other national surveys [43]. Our study was also limited to the data available in MEPS. Although we were able to incorporate several predisposing, enabling, and need factors, MEPS does not include data on clinical outcomes, such as disease activity, or health beliefs. Additionally, utilization of many complementary and alternative therapies is not accounted for in MEPS.

\section{Conclusions}

In conclusion, our study found that trends in annual expenditures for non-Hispanic whites were similar to nonHispanic blacks between 2008 and 2016, but significantly different from Hispanics and other racial minority groups. Additionally, after accounting for healthcare access and functional disability factors, racial and ethnic minorities had significantly lower mean annual expenditures than non-Hispanic whites and delaying needed care was associated with substantially higher costs among adults with arthritis. Our findings provide additional support to the persistence of racial and ethnic differences in healthcare engagement among this population beyond access concerns, as well as the financial burden of delaying needed care. Future research on adults with arthritis should aim to quantify the impact of health beliefs, and the utilization of complementary and alternative therapies, on racial and ethnic differences in healthcare expenditures.

\section{Abbreviations}

ACA: Patient Protection and Affordable Care Act; ADL: Activities of daily living; BMI: Body mass index; CAM: Complementary and alternative medicine; HSP: Hispanic; IADL: Instrumental activities of daily living; MEPS: Medical Expenditure Panel Survey; MSA: Metropolitan statistical area; NHB: NonHispanic black; NHW: Non-Hispanic white; OTH: Non-Hispanic other

\section{Acknowledgements}

Not applicable.

\section{Authors' contributions}

LEE obtained funding for the study. AS, RJW, SN and LEE designed the study. SN and LEE acquired and analyzed the data. AS, SN, and AZD drafted the article. AS, SN, AZD, RJW and LEE critically revised the manuscript for intellectual content. All authors approved the final manuscript.

\section{Funding}

This study was supported by the National Institute of Diabetes and Digestive and Kidney Diseases (K24DK093699, Pl: Egede). 


\section{Availability of data and materials}

The datasets analyzed during the current study are available in the Agency for Healthcare Research and Quality: Medical Expenditure Panel Survey repository, https://meps.ahra.gov/mepsweb/data_stats/download_data_files.jsp [31].

\section{Ethics approval and consent to participate}

Not applicable.

\section{Consent for publication}

Not applicable.

\section{Competing interests}

The authors declare that they have no competing interests.

\section{Author details}

'Department of Epidemiology, Institute for Health and Equity, Medical College of Wisconsin, 8701 Watertown Plank Rd., Milwaukee, WI 53226, USA. ${ }^{2}$ Center for Advancing Population Science, Medical College of Wisconsin, 8701 Watertown Plank Rd., Milwaukee, WI 53226, USA. ${ }^{3}$ Department of Medicine, Division of General Internal Medicine, Medical College of Wisconsin, 8701 Watertown Plank Rd., Milwaukee, WI 53226, USA.

Received: 3 September 2019 Accepted: 3 June 2020

Published online: 12 June 2020

\section{References}

1. Barbour KE, Helmick CG, Boring M, Brady TJ. Vital signs: prevalence of doctor-diagnosed arthritis and arthritis-attributable activity limitation United States, 2013-2015. MMWR Morb Mortal Wkly Rep. 2017;66(9): 246-53.

2. Ma VY, Chan L, Carruthers KJ. Incidence, prevalence, costs, and impact on disability of common conditions requiring rehabilitation in the United States: stroke, spinal cord injury, traumatic brain injury, multiple sclerosis, osteoarthritis, rheumatoid arthritis, limb loss, and back pain. Arch Phys Med Rehabil. 2014;95(5):986-995.e1.

3. Centers for Disease Control and Prevention, USA. Prevalence and most common causes of disability among adults--United States, 2005. MMWR Morb Mortal Wkly Rep. 2009;58(16):421-6.

4. Raval A, Vyas A. Trends in healthcare expenditures among individuals with arthritis in the United States from 2008 to 2014. J Rheumatol. 2018. https://doi.org/10.3899/jrheum.170368.

5. Seed SM, Dunican KC, Lynch AM. Osteoarthritis: a review of treatment options. Geriatrics. 2009;64(10):20-9.

6. Williams EM, Walker RJ, Faith T, Egede LE. The impact of arthritis and joint pain on individual healthcare expenditures: findings from the Medical Expenditure Panel Survey (MEPS), 2011. Arthritis Res Ther. 2017;19(1) Available from: http://arthritis-research.biomedcentral.com/articles/10.1186/ s13075-017-1230-3. Cited 28 Jun 2018.

7. Dominick KL, Dudley TK, Grambow SC, Oddone EZ, Bosworth HB. Racial differences in health care utilization among patients with osteoarthritis. J Rheumatol. 2003;30(10):2201-6.

8. Mikuls TR, Mudano AS, Pulley L, Saag KG. The association of race/ethnicity with the receipt of traditional and alternative arthritis-specific health care. Med Care. 2003:41(11):1233-9.

9. Escalante A, Espinosa-Morales R, Rincón ID, Arroyo RA, Older SA. Recipients of hip replacement for arthritis are less likely to be Hispanic, independent of access to health care and socioeconomic status. Arthritis Rheum. 2000;43(2): 390-9.

10. Figaro MK, Russo PW, Allegrante JP. Preferences for arthritis care among urban African Americans: "I don't want to be cut". Health Psychol. 2004 23(3):324-9.

11. Hoerster KD, Butler DA, Mayer JA, Finlayson T, Gallo LC. Use of conventional care and complementary/alternative medicine among US adults with arthritis. Prev Med. 2012;54(1):13-7.

12. Sandstrom R, Bruns A. Disparities in access to outpatient rehabilitation therapy for African Americans with arthritis. J Racial Ethn Health Disparities. 2017:4(4):599-606

13. Skinner J, Weinstein JN, Sporer SM, Wennberg JE. Racial, ethnic, and geographic disparities in rates of knee arthroplasty among medicare patients. N Engl J Med. 2003;349(14):1350-9.
14. Steel N, Clark A, Lang IA, Wallace RB, Melzer D. Racial disparities in receipt of hip and knee joint replacements are not explained by need: the health and retirement study 1998-2004. J Gerontol A Biol Sci Med Sci. 2008;63(6):629-34.

15. Zhang W, Lyman S, Boutin-Foster C, Parks ML, Pan T-J, Lan A, et al. Racial and ethnic disparities in utilization rate, hospital volume, and perioperative outcomes after total knee arthroplasty. J Bone Joint Surg. 2016;98(15):1243-52.

16. Iversen MD, Schwartz TA, von Heideken J, Callahan LF, Golightly YM, Goode A, et al. Sociodemographic and clinical correlates of physical therapy utilization in adults with symptomatic knee osteoarthritis. Phys Ther. 2018; 98(8):670-8

17. Cisternas MG, Yelin E, Katz JN, Solomon DH, Wright EA, Losina E. Ambulatory visit utilization in a national, population-based sample of adults with osteoarthritis. Arthritis Rheum. 2009;61(12):1694-703.

18. Saha S, Freeman M, Toure J, Tippens KM, Weeks C, Ibrahim S. Racial and ethnic disparities in the VA health care system: a systematic review. J Gen Intern Med. 2008;23(5):654-71.

19. Ibrahim SA, Siminoff LA, Burant CJ, Kwoh CK. Variation in perceptions of treatment and self-care practices in elderly with osteoarthritis: a comparison between African American and white patients. Arthritis Care Res. 2001;45(4): 340-5.

20. Ibrahim SA, Siminoff LA, Burant CJ, Kwoh CK. Differences in expectations of outcome mediate African American/white patient differences in "willingness" to consider joint replacement. Arthritis Rheum. 2002;46(9): 2429-35.

21. Ang DC, Ibrahim SA, Burant CJ, Siminoff LA, Kwoh CK. Ethnic differences in the perception of prayer and consideration of joint arthroplasty. Med Care. 2002;40(6):471-6.

22. Ang DC, Monahan PO, Cronan TA. Understanding ethnic disparities in the use of total joint arthroplasty: application of the health belief model. Arthritis Care Res. 2008;59(1):102-8.

23. Hanchate AD, Zhang Y, Felson DT, Ash AS. Exploring the determinants of racial and ethnic disparities in total knee arthroplasty. Med Care. 2008;46(5): 481-8.

24. Bolen J, Schieb L, Hootman JM, Helmick CG, Theis K, Murphy LB, et al. Differences in the prevalence and impact of arthritis among racial/ethnic groups in the United States, National Health Interview Survey, 2002, 2003, and 2006. Prev Chronic Dis. 2010;7(3) Available from: https://www.ncbi.nlm. nih.gov/pmc/articles/PMC2879996/. Cited 4 Sept 2018.

25. Greenberg JD, Spruill TM, Shan Y, Reed G, Kremer JM, Potter J, et al. Racial and ethnic disparities in disease activity in patients with rheumatoid arthritis. Am J Med. 2013;126(12):1089-98.

26. Stockbridge EL, Suzuki S, Pagán JA. Chronic pain and health care spending: an analysis of longitudinal data from the medical expenditure panel survey. Health Serv Res. 2015:50(3):847-70.

27. Kjeken I, Dagfinrud H, Mowinckel P, Uhlig T, Kvien TK, Finset A. Rheumatology care: involvement in medical decisions, received information, satisfaction with care, and unmet health care needs in patients with rheumatoid arthritis and ankylosing spondylitis. Arthritis Rheum. 2006;55(3): 394-401.

28. Chen J, Vargas-Bustamante A, Mortensen K, Ortega AN. Racial and ethnic disparities in health care access and utilization under the affordable care act. Med Care. 2016:54(2):140-6.

29. Sommers BD, Gunja MZ, Finegold K, Musco T. Changes in self-reported insurance coverage, access to care, and health under the affordable care act. JAMA. 2015;314(4):366-74.

30. Alcalá HE, Chen J, Langellier BA, Roby DH, Ortega AN. Impact of the affordable care act on health care access and utilization among Latinos. J Am Board Fam Med. 2017;30(1):52-62.

31. Agency for Healthcare Research and Quality (AHRQb). Medical expenditure panel survey. 2011 Full year consolidated data file 2013c. 2013. Available from: http://meps.ahrq.gov/mepsweb/data_stats/download_data_files.jsp. Cited 28 Jun 2018

32. Agency for Healthcare Research and Quality. Medical expenditure pane survey background. 2009. Available from: https://meps.ahrq.gov/mepsweb/ about_meps/survey_back.jsp. Cited 20 Feb 2019.

33. Aday LA, Andersen R. A framework for the study of access to medical care. Health Serv Res. 1974:9(3):208-20.

34. Andersen R, Newman JF. Societal and individual determinants of medical care utilization in the United States. Milbank Q. 2005:83(4) Available from: https:// www.ncbi.nlm.nih.gov/pmc/articles/PMC2690261/. Cited 14 Apr 2018. 
35. Manning WG, Mullahy J. Estimating log models: to transform or not to transform? J Health Econ. 2001;20(4):461-94.

36. Belotti F, Deb P, Manning W, Norton E. Tpm: estimating two-part models. Stata J. 2015:15(1):3-20.

37. Egede LE, Walker RJ, Bishu K, Dismuke CE. Trends in costs of depression in adults with diabetes in the United States: Medical Expenditure Panel Survey, 2004 - 2011. J Gen Intern Med. 2016;31(6):615-22.

38. Manning WG, Basu A, Mullahy J. Modeling costs with generalized gamma regression. Chicago: The University of Chicago; 2002.

39. Manning WG, Basu A, Mullahy J. Generalized modeling approaches to risk adjustment of skewed outcomes data. Cambridge: National Bureau of Economic Research; 2003.

40. Lumley T. Analysis of complex survey samples. J Stat Softw. 2004;9(1):1-19.

41. R Core Team. R: a language and environment for statistical computing: $R$ Foundation for Statistical Computing; 2018. Available from: https://www.Rproject.org/. Cited 20 Feb 2019.

42. Molina E, del Rincon I, Restrepo JF, Battafarano DF, Escalante A. Association of socioeconomic status with treatment delays, disease activity, joint damage, and disability in rheumatoid arthritis: socioeconomic status and RA treatment. Arthritis Care Res. 2015;67(7):940-6

43. Murphy LB, Cisternas MG, Greenlund KJ, Giles W, Hannan C, Helmick CG. Defining arthritis for public health surveillance: methods and estimates in four US population health surveys. Arthritis Care Res. 2017;69(3):356-67.

\section{Publisher's Note}

Springer Nature remains neutral with regard to jurisdictional claims in published maps and institutional affiliations.

- fast, convenient online submission

- thorough peer review by experienced researchers in your field

- rapid publication on acceptance

- support for research data, including large and complex data types

- gold Open Access which fosters wider collaboration and increased citations

- maximum visibility for your research: over $100 \mathrm{M}$ website views per year

At $\mathrm{BMC}$, research is always in progress.

Learn more biomedcentral.com/submissions 